\title{
Relationship between Healthy Habits and Perceived Motivational Climate in Sport among University Students: A Structural Equation Model
}

\author{
Ramón Chacón Cuberos ${ }^{1, *(\mathbb{D})}$, Félix Zurita Ortega ${ }^{2}$, Pilar Puertas Molero ${ }^{2}$, Emily Knox ${ }^{3}$ (D), \\ Cristián Cofré Bolados ${ }^{4,5}$, Virginia Viciana Garófano ${ }^{2}$ and José Joaquín Muros Molina ${ }^{2}$ \\ 1 Department of Integrated Didactics, University of Huelva, 21007 Huelva, Spain \\ 2 Department of Didactics of Musical, Plastic and Corporal Expression, University of Granada, \\ 18071 Granada, Spain; felixzo@ugr.es (F.Z.O.); pilarpuertas@correo.ugr.es (P.P.M.); \\ vviciana@ugr.es (V.V.G.); jjmuros@ugr.es (J.M.M.) \\ 3 School of Health Sciences, The University of Nottingham, Nottingham NG7 2RD, UK; \\ Emily.Knox@nottingham.ac.uk \\ 4 School of Sciences of Physical Activity, Sport and Health ECIADES, University of Santiago of Chile, \\ 9170022 Santiago de Chile, Chile; cristian.cofre@usach.cl \\ 5 School of Sports Science and Physical Activity, University Santo Tomas, 837003 Santiago de Chile, Chile \\ * Correspondence: ramon.chacon@ddi.uhu.es; Tel.: +34-958-248-949
}

Received: 17 January 2018; Accepted: 20 March 2018; Published: 23 March 2018

\begin{abstract}
Background: Several studies have shown how certain types of motivation for sports can favour healthy habits or can cause risk behaviours. (2) Methods: The aim of this study was to establish and verify an explanatory model for motivational climate in sport which considers other possible influential variables related to health. This research was conducted with a sample of 490 university students from Spain. The 33-item Perceived Motivational Climate in Sport Questionnaire (PMCSQ-2) was used to assess perceived motivational climate. The Alcohol Use Disorders Identification Test (AUDIT), the Questionnaire of Experiences Related to Video Games (QERV), the Physical Activity Questionnaire for Adolescents (PAQ-A), and the KIDMED test were used to assess healthy habits; (3) Results: Findings revealed that task-involved climate and ego-involved climate were both positively associated with physical activity with the strongest relationship emerging for a task-involved climate. Furthermore, task climate was positively associated with a good adherence to a Mediterranean diet. A direct relationship was found between ego climate and alcohol intake and problematic use of video games; (4) Conclusions: The findings imply that students who have greater intrinsic motivation to participate in sport and perceive a task-involved climate also report healthier habits. This highlights the importance of creating task-involved motivational climates in sport and physical education lessons.
\end{abstract}

Keywords: physical activity; Mediterranean diet; alcohol; video games; sport motivation

\section{Introduction}

The period during which young people attend university is an important stage in the development of behavioural patterns [1]. The lifestyle choices an individual makes are a product of their behaviour and living conditions and includes their relationships with peers, diet, consumption of harmful substances and engagement with physical activity [2,3]. Young people who are just starting university are experiencing a process of transition in which changing social, cultural and economic factors can lead to risky behaviours related to healthy habits [4].

Dietary habits represent a main component of a healthy lifestyle, especially for university students [5]. The eating habits of young people are characterised by a high intake of sugars and 
saturated fats, and insufficient consumption of fruits and vegetables [2]. The Mediterranean diet (MD) is, therefore, of special interest, as it has been shown to have a positive impact on health-related quality of life [6]. The MD is characterised by a high consumption of natural antioxidants, legumes, fish, nuts and olive oil, as well as a moderate intake of meat, eggs and fats [5]. In addition, several studies have shown that dietary habits may influence other habits related to the consumption of harmful substances or time spent engaged in physically active pursuits [7].

Another unhealthy habit that often presents during the university stage of life is the consumption of legal drugs. This is a persistent social issue that has negative effects on health outcomes [8]. It is therefore important to establish risk factors related to excessive drinking at the university stage. Hanewinkel et al. [9] highlight peer influence, erroneous beliefs about the effects of alcohol and its popularity at social events as factors which influence decisions around drinking behaviour. Alcohol can be consumed in an impulsive, social, moderate or compulsive way [10] and can lead to long-term illnesses such as hypertension, cancer, cirrhosis, hepatitis, cardiomyopathy or depression [11]. In this sense, it is essential to promote healthy habits that prevent and/or reduce the consumption of this harmful substance.

Likewise, video game play has become a leisure habit for many sections of the population. Its use has increased most rapidly amongst adolescents and young adults [12]. There is some concern about its pathological use leading to negative effects on academic performance, healthy habits and emotional health [13]. Moreover, misuse of video games has been linked to sedentary habits and high levels of physical inactivity which are associated with overweight and obesity $[12,13]$. To address the deleterious effects associated with video game use and alcohol consumption a number of studies have emphasised the importance of engaging in physical activity and sport. An active lifestyle is associated with a reduced risk of cardiovascular disease, improved lipid profile and lower blood pressure. It can also improve perceived wellbeing, reduce stress and anxiety, and improve memory and controllability [14].

In order to decrease engagement with maladaptive behaviours, the practice of physical activity amongst university students could be an excellent resource, which can improve their quality of life and social health [15]. It is therefore important to identify the motivational factors which are likely to enhance their enjoyment of physical activity and prolong engagement [16]. Achievement goal theory has been successfully employed to explain the motivational processes involved during sport [17]. The model predicts achievement of aims related to sport engagement. It understands that the goals set by individuals are largely dictated by the perception they have of their skills and purpose in sport $[18,19]$. Individuals demonstrate two differentiated conceptions of ability. The first conception of ability is described as task-oriented. Individuals with a task-oriented conception are guided by intrinsic motivations for physical activity and believe that skills are developed through a learning process in which people can progress and improve through effort. The second conception is described as ego-oriented. Individuals with an ego-oriented conception are guided by extrinsic motivations for physical activity and often believe that skill is an entity which cannot be improved. They tend to feel successful when they demonstrate skill through social comparisons [17-20].

Several studies have shown relationships between psychological factors and maladaptive behaviours. This study investigates whether and to what extent certain motivational orientations in a sporting context are related to the healthy habits of university students. The aim of this study was to establish and verify an explanatory model for motivational climate in sport that considers other potentially influential variables related to healthy habits (MD, alcohol consumption, practice of physical activity and problematic use of video games).

\section{Materials and Methods}

\subsection{Subjects and Design}

Participants were recruited from Universities in Granada (Spain) providing courses in Education using an exploratory cross-sectional design. Between 2014 and 2015 there were 628 students enrolled 
on the Physical Education degree programme in Granada (Spain), 442 in a public University and 186 in a private University. All enrolled students were invited to participate in the study. Of these, 528 agreed to participate and provided written informed consent. Thirty eight participants were excluded for failing to complete the questionnaires correctly. This left a final sample of 490 students [ $60.6 \%$ female $(n=297), 39.4 \%$ male $(n=193)]$ with a mean age of $22.8 \pm 3.63$ years old (range: 20 to 29$)$.

\subsection{Measures}

\subsubsection{Motivational Climate in Sport}

Perceived motivational climate in sport was evaluated using the 33-item Perceived Motivational Climate in Sport Questionnaire (PMCSQ-2, [21]) alongside the Spanish validation form of GonzálezCutre et al. [22]. For each item participants responded using a five-point scale ranging from 1, strongly disagree, to 5 , strongly agree. The questionnaire comprised two higher-order scales (task and ego), each containing three subscales (task: cooperative learning, effort/improvement, important role; ego: member rivalry, unequal recognition, punishment for mistakes). Internal consistency of the data was assessed using Cronbach's alpha and was acceptable for both perceived task and perceived ego climate subscales ( $\alpha=0.810$ and $\alpha=0.790$, respectively).

\subsubsection{Alcohol Consumption}

Consumption of alcohol was assessed using the Alcohol Use Disorders Identification Test (AUDIT) [23] which has been translated into Spanish by Rubio [24]. AUDIT is composed of 10 items. The first eight items are evaluated using a five-point Likert scale (Never $=0$; Daily $=4)$. The last two items are evaluated using a three-point Likert scale which produces a point score of 0,2 or 4 points. The first three items of the AUDIT describe the frequency of consumption, the next three items describe the level of dependence and the remaining four items are related to harmful consumption. The overall score lies in the range of 0 to 40 . Scores from 0-10 describe a low consumption of alcohol, while scores from 11-30 describe medium consumption of alcohol. Scores from 31-40 highlight a high consumption of alcohol. The data produced a Cronbach's alpha of $\alpha=0.767$.

\subsubsection{Problematic Use of Video Games}

Problematic use of video games was assessed using the Questionnaire of Experiences Related to Video Games (QERV), which was developed by Chamarro et al. [25] and has been validated in a sample of Spanish teenagers. The QERV consists of 17 negatively worded items rated on a four-point Likert scale $(\mathrm{a}=$ Hardly ever; $\mathrm{b}=$ Sometimes; $\mathrm{c}=$ often; $\mathrm{d}=$ Always). Responses are summed to create a variable which describes participant's behaviour relating to video game use with a range of 17-68. For this variable, scores between 17 and 25 describe no problems with video games, while scores between 26 and 38 suggest potential problems. Finally, scores between 39 and 68 describe severe problems with these devices. The Cronbach's alpha obtained was $\alpha=0.896$.

\subsubsection{Physical Activity}

Physical activity levels were evaluated using the Physical Activity Questionnaire for Adolescents (PAQ-A; [26]). The questionnaire assesses the frequency and type of physical activity engaged in during the seven days prior to completing the questionnaire. The final score is calculated from the mean of the 10 items, with each item being evaluated on a five-point Likert scale (Never $=0$; Always $=5$ ). The overall score lies in the range of 0 to 50 . Scores between $0-12$ describe a very low level of physical activity, while scores between 13 and 25 establish a low level. Scores between 26 and 35 describe a medium level of physical activity and scores between 36 and 50 a high level. For this instrument, the Cronbach's alpha obtained was $\alpha=0.797$. 


\subsubsection{Adherence to Mediterranean Diet}

Adherence to the Mediterranean diet was assessed using the Evaluation of Mediterranean Diet Index (KIDMED). KIDMED estimates adherence to the Mediterranean diet in children and young adults [27]. The questionnaire comprises 16 dichotomous items (yes or no). The overall score lies in the range of -4 to 12 . Scores between -4 and 1 describe low adherence to $\mathrm{MD}$, while scores between 2 and 7 suggest the need to improve their diet. Scores from 8 to 12 describe a high quality diet. Internal consistency of the data was assessed using Cronbach's alpha and was acceptable $(\alpha=0.821)$.

\subsection{Procedure}

Participants were instructed on how to fill out the questionnaires. All tests were conducted during a non-teaching lesson at the student's university. No incentives were provided to participants. A research assistant was on hand to provide guidance on the completion of questionnaires. Ethical approval was granted by the Ethics Committee of the University of Granada [462/CEIH/2017]. Ethical principles of the Declaration of Helsinki for medical research were adhered to.

\subsection{Statistical Analysis}

Data were analysed using SPSS ${ }^{\circledR}$ version 22.0 (IBM Corp, Armonk, NY, USA) for Windows. Descriptive analysis was performed using frequencies and averages. Associative analysis was conducted using the Pearson Chi-square test. The significance level was set at 0.05 . Statistical models with instructive equations at the latent variable level were created using AMOS version 23.0. Structural Equation Modelling (SEM) was used to analyse the relationships between perceived motivational climate in sport, physical activity, alcohol use, adherence to a Mediterranean diet and problematic use of video games (Figure 1).

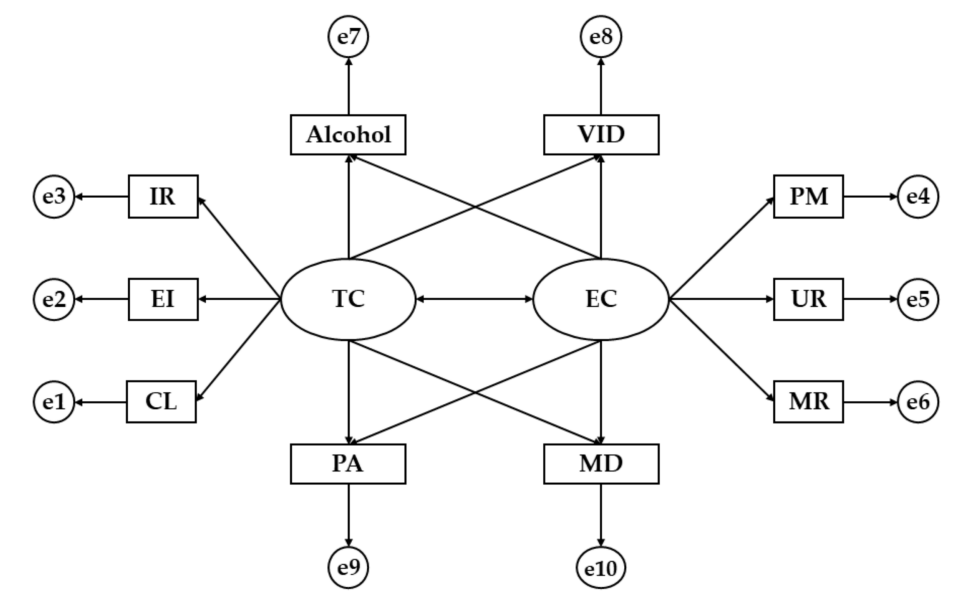

Figure 1. Model theories. Note: TC, Task Climate; EC, Ego Climate; CL, Cooperative Learning; EI, Effort/Improvement; IR, Important Role; PM, Punishment for Mistakes; UR, Unequal Recognition; MR, Member Rivalry; MD, Mediterranean Diet; PA, Physical Activity; VID, Video games.

The SEM for this data is characterized by ten observed variables and two latent variables. This model makes causal explanations of the latent variables from the observed relationships between indicators. The squares represent the observed variables and the circles represent the error terms. Ovals are used to indicate the latent variables. The exogenous latent variables, task-involved climate (TC) and ego-involved climate (EC), were each inferred using three indicators. For task these were: Cooperative learning (CL), effort/improvement (EI), and important role (RI). For ego these were: Member rivalry (MR), unequal recognition (UR), and punishment for mistakes (PM). Physical activity (PA), adherence to Mediterranean diet (MD), alcohol consumption (Alcohol), and problematic use of videogames (VID) were the observed endogenous variables. 
The bi-directional arrow (covariance) relates exogenous variables, while the unidirectional arrows are lines of influence between the latent and observable indicators, and are interpreted as multivariate regression coefficients. In addition, error prediction terms are associated with endogenous variables. The method of maximum likelihood (ML) was use to estimate relationships between variables. We chose this method because it is consistent, unbiased and invariant to types of scale given variables with a normal distribution.

Model fit was examined to verify the compatibility of the proposed model and the empirical information gathered. Goodness of fit was tested using a number of indices briefly described here [28]. Chi-squared analysis followed when non-significant $p$-Values indicated good model fit. Comparative fit index (CFI), normalized fit index (NFI) and increase fit index (IFI) values higher than 0.90 indicate acceptable model fit while values higher than 0.95 indicate excellent model fit. Root mean square error of approximation (RMSEA) values below 0.08 indicate acceptable model fit while values below 0.05 indicate excellent model fit.

\section{Results}

Almost all indices of model fit suggested good fit. A significant chi-square value was obtained $\left(\chi^{2}=97.59 ; \mathrm{df}=30 ; p<0.001\right)$, however, as this index has no upper limit and may also be sensitive to sample size, we also considered other standardized indices which are less sensitive to sample size [29]. The normalized fit index (NFI) was 0.931 , indicating an acceptable fit to the model. The comparative fit index (CFI) and the increase fit index (IFI) yielded a value of 0.951 for both, indicating an excellent fit to the model. The root mean square error of approximation RMSEA value was 0.70 , indicating acceptable fit [30]. In summary, data suggests that the model fits the empirical data well.

Figure 2 shows the direct effects between variables as well as the bi-directional effect between task climate and ego climate on the independent variable. Table 1 shows the standardized weights of saturation between the latent variables and their indicators as well as with the variables related to alcohol use, problematic use of video games, physical activity, and adherence to a Mediterranean diet. A significant negative relationship was found between the two dimensions of motivational climate: task-involved climate and ego-involved climate $(r=-0.48)$. Further, the three factors defining each dimension of motivational climate (task-involved climate: important role, effort/improvement, collaborative learning; ego-involved climate: punishment for mistakes, unequal recognition, member rivalry) were positively and strongly related to their respective dimension.

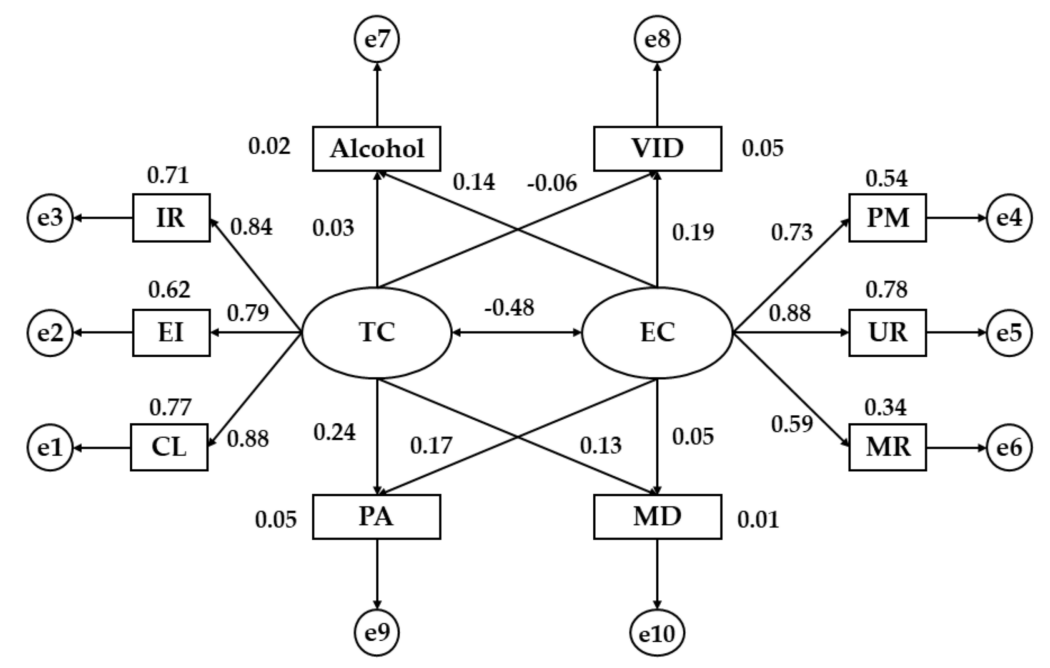

Figure 2. Structural equation model with regression weights. Note: TC, Task Climate; EC, Ego Climate; CL, Cooperative Learning; EI, Effort/Improvement; IR, Important Role; PM, Punishment for Mistakes; UR, Unequal Recognition; MR, Member Rivalry; MD, Mediterranean Diet; PA, Physical Activity; VID, Video games. 
Table 1. Weights and standardized regression weights.

\begin{tabular}{ccccccc}
\hline \multirow{2}{*}{ Relationship between Variables } & \multicolumn{2}{c}{ R.W. } & & & S.R.W. \\
\cline { 4 - 7 } & & & Estimations & S.E. & C.R. & Estimations \\
\hline CL & $\leftarrow$ & TC & 1.000 & - & - & 0.877 \\
EI & $\leftarrow$ & TC & 0.818 & 0.041 & 19.746 & $0.786^{* * *}$ \\
IR & $\leftarrow$ & TC & 0.979 & 0.046 & 21.179 & $0.840^{* * *}$ \\
PM & $\leftarrow$ & EC & 1.000 & - & - & 0.735 \\
UR & $\leftarrow$ & EC & 1.412 & 0.099 & 14.316 & $0.883^{* * *}$ \\
MR & $\leftarrow$ & EC & 0.927 & 0.078 & 11.915 & $0.587^{* * *}$ \\
Alcohol & $\leftarrow$ & TC & 0.021 & 0.046 & 0.445 & 0.025 \\
Alcohol & $\leftarrow$ & EC & 0.125 & 0.053 & 2.355 & $0.137^{*}$ \\
MD & $\leftarrow$ & EC & 0.048 & 0.058 & 0.820 & 0.048 \\
MD & $\leftarrow$ & TC & 0.117 & 0.051 & 2.299 & $0.131^{*}$ \\
PA & $\leftarrow$ & TC & 0.289 & 0.069 & 4.173 & $0.237^{* * *}$ \\
PA & $\leftarrow$ & EC & 0.230 & 0.079 & 2.896 & $0.168^{* *}$ \\
VID & $\leftarrow$ & EC & 2.331 & 0.694 & 3.360 & $0.194^{* * *}$ \\
VID & $\leftarrow$ & TC & -0.636 & 0.601 & -1.142 & -0.064 \\
EC & $\leftrightarrow$ & TC & -0.146 & 0.019 & -7.612 & $-0.479^{* * *}$ \\
\hline
\end{tabular}

Note 1: R.W., Regression Weights; S.R.W., Standardized Regression Weights; S.E., Estimation of Error; C.R., Critical Ratio; Note 2: TC, Task Climate; EC, Ego Climate; CL, Cooperative Learning; EI, Effort/Improvement; IR, Important Role; PM, Punishment for Mistakes; UR, Unequal Recognition; MR, Member Rivalry; MD, Mediterranean Diet; PA, Physical Activity; VID, Video games. Note $3:{ }^{*}, p<0.05 ;{ }^{* *}, p<0.01 ;{ }^{* * *}, p<0.001$.

A task-involved climate $(p<0.001 ; r=0.24)$ and ego-involved climate $(p<0.01 ; r=0.17)$ were both positively associated with physical activity with the strongest relationship emerging for a task-involved climate. Moreover, task climate showed a direct relationship with MD $(p<0.05 ; r=0.13)$ while ego climate did not reveal any association. On the other hand, ego climate was positively related to alcohol intake $(p<0.05 ; r=0.14)$ and problematic use of video games $(p<0.001 ; r=0.19)$. Task-involved climate was not related to these two behaviours.

\section{Discussion}

The present research presents a two-dimensional model of perceived motivational climate in sport (task climate and ego climate) in university students. Furthermore, to our knowledge, this is the first study which examines relationships between motivational climate and healthy habits, such as practice of physical activity, adherence to the MD, alcohol consumption and problematic use of video games. The proposed structural equation model adjustments were informed by a number of national and international research findings in recent years [31-34].

The present research corroborates existing literature identifying an indirect relationship between task-involved and ego-involved climates [16,34]. This is logical as the two climates adhere to contrasting motivational types in sport. Task climate is related to intrinsic motivations, such as interest in the learning process or cooperative work. On the contrary, ego climate is associated with different extrinsic motivations and seeking to obtain better performance with the minimum effort or greater social recognition than other competitors $[19,20]$.

With regards to the strength of relationships found within both motivational climates and their corresponding indicators, cooperative learning most strongly defined perceptions of a task-involved climate, with effort/improvement being the indicator with the least influence. Perceptions of an ego-climate were mostly defined by unequal recognition. This is unsurprising given the psychological characteristics which commonly emerge during the transition from university to adulthood [1,4] and is further supported by previous findings, for instance in the study by Newton et al. [21], which suggests that improvement in sports may be linked to a greater need for competition.

The present study found a task-involved climate to be more highly correlated with healthy habits than ego-involved climate. A positive correlation was observed between both types of motivational 
climate and physical activity, though this relationship was stronger for task climate. Research conducted by Almagro et al. [35] found a task-involved orientation to positively predict basic psychological needs related to the intention to be physically active and intrinsic motivations for physical activity practice. This could at least partially explain the greater association between task-involved achievement goals and sport practice. As in the present research, this aforementioned research also failed to find relationships between the intention to be physically active and the subcategories of ego climate.

Task climate was positively associated with adherence to a MD, while ego climate was not related. Bruin et al. [31] uncovered links between ego involvement and disordered eating in relation to competitiveness and referenced comparisons. They found a negative relationship between task involvement and disordered eating. One explanation for this is that task-involved individuals are less likely to make physical comparisons with partners and to have the intention to start dieting for performance enhancement. Similarly, Moreno-Gómez et al. [3] studied the relationship between healthy habits such as diet quality and physical activity in Spanish university students and highlighted the importance of developing nutritional education campaigns that include promotion of physical activity practice to improve the overall health status of this population group.

A further finding from the present research was that ego climate was directly related to alcohol consumption. Moreover, task climate was not associated with this variable. Chan et al. [36] also obtained a positive relationship between alcohol and tobacco consumption and ego climate in a sample of adolescents. One explanation for this is that young people with ego-oriented goals have less self-determined motivations towards sport and less adaptive patterns for sport practice [18,37-39]. In the long-term such individuals are more likely to develop harmful behavioural habits such as engaging in sedentary leisure pursuits or consuming legal drugs such as alcohol or tobacco $[13,36,40]$.

Finally, the problematic use of video games was positively related to the ego-involved climate. Adachi et al. [41] established that the use of video games allows achieving a sense of victory, improving self-esteem or competing with other rivals. In this sense, it can be seen how these devices implies many of the competence needs developed in the Self-Determination Theory in a similar way to how it is done in sports practice [37], which would justify the relationship between ego-involved climate and the use of video games. In this sense, task-oriented climate could act as a protective factor against this type of maladaptive behaviour [42].

The present research is limited by its descriptive cross-sectional design, which precludes conclusions on causality or directionality from being made. In addition, it would have been interesting to expand the spectrum of examined variables associated with psychosocial factors to consider self-concept, motivation or self-esteem, all of which have been previously related to psychosocial outcomes of physical activity.

\section{Conclusions}

The findings reveal a positive relationship between both dimensions of motivational climate and physical activity, this relationship being stronger for task climate. Furthermore, task climate was positively associated with a good adherence to a MD. On the contrary, a direct relationship was found between ego climate and unhealthy habits, such as alcohol consumption and problematic use of video games. The findings encourage training physical education teachers to take a broad perspective of different healthy habits. The aim should be to develop an appropriate motivational climate for sport within physical education lessons. In this sense, teachers should strive to promote cooperative work and an interest for learning in order to play an important role in physical sport practice.

Acknowledgments: This work was supported by Precompetitive Research Projects for Young Researchers 2017-Modality B under de Grant PPJIBB-05, the project “DISPERSA" under the Grant TIN2015-67149-C3-R and European Regional Development Fund (ERDF) under the Grant P11-TIC-7486. 
Author Contributions: Ramón Chacón Cuberos and Félix Zurita Ortega conceived the hypothesis of this study. Félix Zurita Ortega, Pilar Puertas Molero y Cristian Cofré Bolados participated in data collection. Ramón Chacón Cuberos y José Joaquín Muros Molina analysed the data. All authors contributed to data interpretation of statistical analysis. Ramón Chacón Cuberos, José Joaquín Muros Molina and Emily Knox wrote the paper with significant input from Félix Zurita Ortega. All authors read and approved the final manuscript.

Conflicts of Interest: The authors declare no conflict of interest.

\section{References}

1. Wei, C.N.; Harada, K.; Ueda, K.; Fukumoto, K.; Minamoto, K.; Ueda, A. Assessment of health-promoting lifestyle profile in Japanese university students. Environ. Health Prev. Med. 2012, 17, 222-227. [CrossRef] [PubMed]

2. Deliens, T.; Clarys, P.; De Boudeaudhuij, I.; Deforche, B. Determinants of eating behaviour in university students: A qualitative study using focus group discussions. BMC Public Health 2014, 14, 1-12. [CrossRef] [PubMed]

3. Moreno-Gómez, C.; Romaguera-Bosch, D.; Tauler-Riera, P.; Bennasar-Veny, M.; Pericas-Beltrán, J. Clustering of lifestyle factors in Spanish university students: The relationship between smoking, alcohol consumption, physical activity and diet quality. Public Health Nutr. 2012, 15, 2131-2139. [CrossRef] [PubMed]

4. Tosevski, D.L.; Milovancevic, M.P.; Gajic, S.D. Personality and psychopathology of university students. Curr. Opin. Psychiatry 2010, 23, 48-52. [CrossRef] [PubMed]

5. Papadaki, A.; Hondros, G.; Scott, J.A.; Kapsokefalou, M. Eating habits of University students living at, or away from home in Greece. Appetite 2007, 49, 169-176. [CrossRef] [PubMed]

6. Petroka, K.; Dinu, M.; Hoover, C.; Casini, A.; Sofi, F. Short-term Exposure to a Mediterranean Environment Influences Attitudes and Dietary Profile in US College Students: The Mediterranean Diet in Americans (A-MED-AME) Pilot Study. J. Am. Coll. Nutr. 2016, 35, 621-626. [CrossRef] [PubMed]

7. Arriscado, D.; Muros, J.J.; Zabala, M.; Dalmau, J.M. Factors associated with low adherence to Mediterranean diet in healthy children in northern Spain. Appetite 2014, 80, 28-34. [CrossRef] [PubMed]

8. Conway, K.P.; Green, V.R.; Kasza, K.A.; Silveira, M.L.; Borek, N.; Kimmel, H.L.; Sargent, J.D.; Stanton, C.; Lambert, E.; Hilmi, N.; et al. Co-occurrence of tobacco product use, substance use, and mental health problems among adults: Finding from Wave 1 (2013-2014) of the population assessment of tobacco and health (PATH) study. Drug Alcohol Depend. 2017, 177, 104-111. [CrossRef] [PubMed]

9. Hanewinkel, R.; Sargent, J.D.; Poelen, E.A.; Scholte, R.; Florek, E.; Sweeting, H.; Hunt, K.; Karlsdottir, S.; Mathis, F.; Faggiano, F.; et al. Alcohol consumption in movies and adolescent binge drinking in 6 European countries. Pediatrics 2012, 129, 1-12. [CrossRef] [PubMed]

10. Stautz, K.; Cooper, A. Impulsivity-related personality traits and adolescent alcohol use: A meta-analytic review. Clin. Psychol. Rev. 2013, 33, 574-592. [CrossRef] [PubMed]

11. McCambridge, J.; McAlaney, J.; Rowe, R. Adult Consequences of Late Adolescent Alcohol Consumption: A Systematic Review of Cohort Studies. PLoS Med. 2011, 8, e1000413. [CrossRef] [PubMed]

12. Festl, R.; Scharkow, M.; Quadt, T. Problematic computer game use among adolescents, younger and older adults. Addiction 2013, 108, 792-799. [CrossRef] [PubMed]

13. Anderson, C.A.; Shibuya, A.; Ihori, N.; Swing, E.L.; Bushman, B.J.; Sakamoto, A.; Rothstein, H.R.; Muniba, S. Violent video game effects on aggression empathy, and prosocial behaviour in eastern and western countries: A meta-analytic review. Psychol. Bull. 2010, 136, 151-173. [CrossRef] [PubMed]

14. Verburgh, L.; Königs, M.; Scherder, E.J.; Oosterlaan, J. Physical exercise and executive functions in preadolescent children, adolescents and young adults: A meta-analysis. Br. J. Sports Med. 2013, 1-8. [CrossRef] [PubMed]

15. Georgian, B.; Lorand, B. The influence of leisure sports activities on social health in adults. SpringerPlus 2016, 5, 1647. [CrossRef] [PubMed]

16. MacDonal, D.J.; Cote, J.; Eys, M.; Deakin, J. The role of enjoyment and motivational climate in relation to the personal development of team sport athletes. Sport Psychol. 2011, 25, 32-46. [CrossRef]

17. Hulleman, C.S.; Schrager, S.M.; Bodmann, S.M.; Harackiewicz, J.M. A meta-analytic review of achievement goal measures: Different labels for the same constructs or different constructs with similar labels? Psychol. Bull. 2010, 136, 422-449. [CrossRef] [PubMed] 
18. Keegan, R.J.; Harwood, C.G.; Spray, C.M.; Lavalle, D. A qualitative investigation of the motivational climate in elite sport. Psychol. Sport Exerc. 2014, 15, 97-107. [CrossRef]

19. Méndez-Giménez, A.; Fernández-Río, J.; Cecchini-Estrada, J.A.; González, C. Motivational profiles and their outcomes in physical education. A complementary study on 2x2 achievement goals. J. Psychol. Sport 2013, 22, 29-38.

20. Bortoli, L.; Bertollo, M.; Comani, S.; Robazza, C. Competence, achievement goals, motivational climate, and pleasant psychobiosocial states in youth sport. J. Sport Sci. 2011, 29, 171-180. [CrossRef] [PubMed]

21. Newton, M.; Duda, J.; Yin, Z. Examination of the psychometric properties of the Perceived Motivational Climate in Sport Questionnaire-2 in a sample of female athletes. J. Sport Sci. 2000, 18, 275-290. [CrossRef] [PubMed]

22. González-Cutre, D.; Sicilia, A.; Moreno, J.A. Social-cognitive model of goal motivation in Physical Education. Psicothema 2008, 20, 642-651.

23. Saunders, J.; Aasland, O.; Babor, T.; De la Fuente, J.; Grant, M. Development of the Alcohol Use Disorders Identification Test (AUDIT): Who collaborative Project on early detection of persons with harmful alcohol consumption-II. Addiction 1993, 88, 791-804. [CrossRef] [PubMed]

24. Rubio, G. Validation test for identifying disorders related to alcohol use (AUDIT) in primary care. Spec. Clin. J. 1998, 198, 11-14.

25. Chamarro, A.; Carbonell, X.; Manresa, J.M.; Muñoz-Mirallles, R.; Ortega-González, R. The Questionnaire of Experiences Associated with Video Games (CERV): An instrument to detect the problematic use of video games in Spanish adolescents. Adicciones 2014, 26, 303-311. [CrossRef] [PubMed]

26. Kowalski, K.C.; Crocker, P.R.; Donen, R.M. The physical activity questionnaire for older children (PAQ-C) and adolescents (PAQ-A) manual. Coll. Kinesiol. 2004, 87, 1-38.

27. Serrá-Majem, L.; Ribas, L.; Ngo, J.; Ortega, R.M.; García, A. Food, youth and the Mediterranean diet in Spain. Development of KIDMED, Mediterranean diet quality index in children and adolescents. Public Health Nutr. 2004, 7, 931-935. [CrossRef] [PubMed]

28. Marsh, H.W. Handbook of Sport Psychology, 3rd ed.; Wiley: Hoboken, NJ, USA, 2007; pp. 157-164.

29. Jöreskog, K.G. Structural Equation Models in the Social Sciences: Specification Estimation and Testing; North-Holland Publishing Company: Amsterdam, The Netherlands, 1997; pp. 265-287.

30. Browne, M.W.; Cudeck, R. Testing Structural Equation Models; Sage Publications Inc.: Beverly Hills, CA, USA, 1993; pp. 69-82.

31. Bruin, A.P.; Bakker, F.; Oudejans, R. Achievement goal theory and disordered eating: Relationships of disordered eating with goal orientations and motivational climate in female gymnasts and dancers. Psychol. Sport Exerc. 2009, 10, 72-79. [CrossRef]

32. Jöesaar, H.; Hein, V.; Hagger, M. Youth athletes' perception of autonomy support from the coach, peer motivational climate and intrinsic motivation in sport setting: One-year effects. Psychol. Sport Exerc. 2012, 13, 257-262. [CrossRef]

33. Moreno-Murcia, J.A.; Hellín, P.; González-Cutre, D.; Martínez-Galindo, C. Influence of Perceived Sport Competence and Body Attractiveness on Physical Activity and other Healthy Lifestyle Habits in Adolescents. Span. J. Psychol. 2011, 14, 282-292. [CrossRef] [PubMed]

34. Zurita-Ortega, F.; Muros-Molina, J.J.; Rodríguez-Fernández, S.; Zafra-Santos, E.O.; Knox, E. Associations of motivation, self-concept and resilience with the competitive level of Chilean judokas. Arch. Budo 2016, 12, 201-209.

35. Almagro, B.J.; Saénz-López, P.; González-Cutre, D.; Moreno-Murcia, J.A. Perceived motivational climate, psychological needs and intrinsic motivation as Predictors of sport commitment in adolescent athletes. RICYDE 2011, 25, 250-265. [CrossRef]

36. Chan, D.K.; Dimmock, J.A.; Donovan, R.J.; Hardcastle, S.; Lentillon-Kaestner, V.; Hagger, M.S. Self-determined motivation in sport predicts anti-doping motivation and intention: A perspective from the trans-contextual model. J. Sci. Med. Sport 2015, 18, 315-322. [CrossRef] [PubMed]

37. Chacón, R.; Zurita, F.; Castro, M.; Espejo, T.; Martínez, A.; Cortés, A.J.P. Motivational climate in sport and its relationship with digital sedentary leisure habits in university students. Saude Soc. 2017, 26, 29-39. [CrossRef]

38. González-Valero, G.; Zurita-Ortega, F.; Martínez-Martínez, A. Panorama motivacional de actividad física en estudiantes: Una revisión sistemática. ESHPA 2017, 1, 56-79. 
39. Erturan-Ilker, G.; Yu, C.; Alemdaroğlu, U.; Köklü, Y. Basic psychological needs and self-determined motivation in PE to predict health-related fitness level. J. Sport Health Res. 2018, 10, 91-100.

40. López, G.F.; Ahmed, D.; Díaz, A. Level of habitual physical activity among 13-year-old adolescents from Spain and India. A cross-cultural study. Sport TK 2017, 6, 67-74.

41. Adachi, P.; Willoughby, T. Does playing sport video games predict increased involvement in real-life sports over several years among older adolescents and emerging adults? J. Youth Adolesc. 2016, 45, 391-401. [CrossRef] [PubMed]

42. Martins, J.; Torres, B.; Cardoso, J.; Costa, A.M.; Honório, S. Influence of sociological aspects on the level of physical activity in physical education students. J. Hum. Sport Exerc. 2015, 10, 815-826. [CrossRef]

2018 by the authors. Licensee MDPI, Basel, Switzerland. This article is an open access article distributed under the terms and conditions of the Creative Commons Attribution (CC BY) license (http://creativecommons.org/licenses/by/4.0/). 